Mrozkowiak Mirosław. The evaluation of the impact of flexion and extension angles and lateral torso flexion on the selected spine and pelvis parameters. Pedagogy and Psychology of Sport. 2021;7(2):51-65. elSSN 2450-6605. DOI http://dx.doi.org/10.12775/PPS.2021.07.02.004

https://apcz.umk.pl/czasopisma/index.php/PPS/article/view/PPS.2021.07.02.004

https://zenodo.org/record/4741204

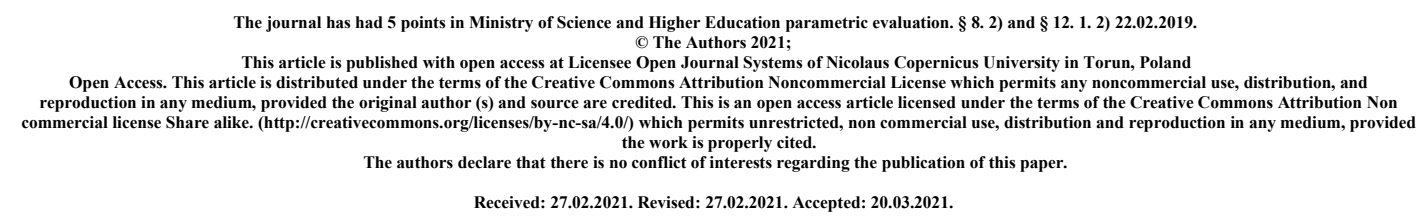

THE EVALUATION OF THE IMPACT OF FLEXION AND EXTENSION ANGLES AND LATERAL TORSO FLEXION ON THE SELECTED SPINE AND PELVIS PARAMETERS

\title{
Mirosław Mrozkowiak
}

Physiotherapy Practice AKTON, Poznań, Poland

\begin{abstract}
The aim of the research was to assess the impact of flexion and extension angles and lateral torso flexion on the selected spine and pelvis parameters among the population of children aged between 7 and 15 years.
\end{abstract}

Material and methods. The research was conducted in randomly selected kindergartens and schools in the Warmia and Masuria region and the Pomerania region during six semi-annual editions. The study population consisted of 2,361 children. This allowed recording 16,608 observations of 31 parameters describing body posture using the photogrammetric method.

Results. The analysis of multiple regression with the selection of the subset of the optimal set of variables included four parameters affecting the following: flexion angle and extension angle in the sagittal plane, angle of flexion to the left, and the right in the frontal plane. The set of variables included the parameters of the pelvis-spine complex.

\section{Conclusions}


1. Spinal parameters are significantly and positively affected by the angle of torso extension in the sagittal plane and the angle of flexion to the left in the frontal plane and negatively influenced by the flexion angle in the sagittal plane.

2. The values of torso extension and flexion angles in the sagittal plane and torso flexion to the left and right in the frontal plane have a significant and positive impact on the total length of the spine $\left(\mathrm{C}_{7}-\mathrm{S}_{1}\right)$ and the percentage of growth $(\mathrm{DCK} \%)$, the Delta angle and the height of lumbar lordosis. The inclination angle of the lumbosacral spine, the total spinal length, and the percentage of body height and the height of lumbar lordosis account for the parameters that are most dependent on the angles describing the vertical orientation of the axial organ.

3. The significant negative impact on the spine parameters is remarkably lower. The most negatively dependent parameters include lumbosacral inclination angle, the length and angle of thoracic kyphosis, and lumbar lordosis angle.

4. Hardly any influence of the analysed angles on pelvis parameters demonstrated herein requires further studies on the impact of foot parameters on the parameters of pelvis and spine.

5. The significant correlations of flexion and extension angles in the sagittal plane, as well as the flexion angle in the frontal plane, should be taken into consideration in the process of correcting body posture defects and errors.

Key words: mora projection, spine and pelvis parameters

\section{Introduction}

Everything that undermines health basics and destroys the harmony of the musculoskeletal structure poses a potential risk to correct body posture and should be prevented [1]. The body posture image undergoes changes not only over time but also gets modified during the day under the influence of emotions, mental and physical state. The axis of the torso determining its structure and activity is the spine which rests on the sacrum that forms part of the pelvis. There are few publications mentioning the mutual relationships between the spine and other musculoskeletal elements. These issues have been studied by Mrozkowiak, Jazdończyk [2], Mrozkowiak, Cybul [3], Mrozkowiak at al. [4], Mrozkowiak, Sokołowski [5], Sokołowski, Mrozkowiak [6], Mrozkowiak at al. [7], Mrozkowiak at al. [8], and Mrozkowiak et al. [9]. 
This subject matter requires a holistic approach to the human body in the context of correlations between particular elements of the musculoskeletal system. Therefore, the human body shall be seen as the system of biomechanical myofascial-ligamentous chains within the muscular, skeletal and nervous system with the pelvis in the centre providing the basis for the biomechanical functioning of the body. As far as functionality is concerned, pelvic stability shall be considered along with the spatial orientation of the axial organ, hip joints and foot positioning as its stability plays a key role during physical activity.

The spiral band consists of two helico-myofascial bands that wrap around the body. This myofascial continuity is composed of surface muscles. Being on the entire length, it has some elements in common with three other surface bands including the anterior, posterior and lateral ones. The upper spiral band runs from the right side of the head, under the armpit, around the anterior stomach wall to the right hip. The band begins on the right side of the head with muscle flap in the head and neck, then it runs over the spinous process of the lower cervical and upper thoracic vertebrae to reach the rhomboid muscles on the other side of the spine, then under the medial edge of the scapula into the serratus anterior muscle which blends into the oblique. Its natural fascial continuity is the internal oblique abdominal muscle on the other side. The lower band begins on the anterior superior iliac spine and the iliac crest. Then it runs down going into the anterior part of the iliotibial band and joining the tibialis anterior. Being in the common fascial bag with extensors of toes and the great toe, it goes under the retinacula, into the inner part of the foot ending up in the articular capsule of the first metatarsal and medial cuneiform bone. The long fibular muscle emerges from the same place from the outside of the tendon, forming with the anterior tibial muscle a kind of "a stirrup" with a footer under the foot. The long fibular muscle in the common fascia with the short fibular muscle goes upwards reaching the head of the fibula. The fascial connection of the fibular muscle with the short head of the thigh biceps muscle runs up to the tuber ischium of the pelvic bone [10]. Thus, in accordance with the concept of the helical spiral band, the axial organ should have an impact on other parameters of the spine and pelvis.

The aim of the research was to assess the impact of flexion and extension angles and lateral torso flexion on the selected spine and pelvis parameters among the population of children aged between 7 and 15 years.

\section{Material and methods}

Research on body posture was conducted in randomly selected kindergartens and schools in the Warmia and Masuria region and the Pomerania region. The study population consisted of 
2,361 children. The study involved $46.84 \%$ boys (1106 subjects) and $53.15 \%$ girls (1255 subjects). The advantage of girls was at the level of 149 individuals which accounted for 6.31\%. The subjects included 69.97\% (1652 people) from urban areas, 52.11\% girls (861 people) and $47.88 \%$ boys (791 people), 30.03\% from rural areas (709 people) including $55.57 \%$ girls (394 people), $44.42 \%$ boys (315 people), Tab. 1 .

Tab. 1. Number of observations in age and sex categories

\begin{tabular}{|c|c|c|c|}
\hline & \multicolumn{3}{|c|}{ Number of observations } \\
\hline \multirow{2}{*}{$\begin{array}{l}\text { Age } \\
\text { (years) }\end{array}$} & \multicolumn{2}{|c|}{ Sex } & \multicolumn{1}{l}{$\begin{array}{l}\text { Sum } \\
(\mathrm{N})\end{array}$} \\
\hline 7 & 610 & 597 & 1207 \\
\hline 8 & 1341 & 1255 & 2596 \\
\hline 9 & 1839 & 1677 & 3516 \\
\hline 10 & 1752 & 1542 & 3294 \\
\hline 11 & 1047 & 901 & 1948 \\
\hline 12 & 670 & 549 & 1219 \\
\hline 13 & 569 & 462 & 1031 \\
\hline 14 & 582 & 436 & 1018 \\
\hline 15 & 424 & 355 & 779 \\
\hline Total & 8834 & 7774 & 16608 \\
\hline
\end{tabular}

Source: own study 
Tab. 2. Parameters

\begin{tabular}{|c|c|c|c|c|}
\hline \multirow[t]{2}{*}{ No. } & \multirow[t]{2}{*}{ Symbol } & \multicolumn{3}{|c|}{ Parameters } \\
\hline & & Unit & Name & Description \\
\hline \multicolumn{5}{|c|}{ Sagittal plane } \\
\hline 1 & Alfa & degrees & \multicolumn{2}{|c|}{ Inclination of lumbo-sacral region } \\
\hline 2 & Beta & degree & \multicolumn{2}{|c|}{ The inclination of the thoracolumbar region } \\
\hline 3 & Gamma & degree & \multicolumn{2}{|c|}{ The inclination of the upper thoracic region } \\
\hline 4 & Delta & degree & The sum of angles & Delta $=$ Alfa + Beta + Gamma \\
\hline 5 & DCK & $\mathrm{mm}$ & \multirow[t]{2}{*}{$\begin{array}{l}\text { The total length of } \\
\text { the spine }\end{array}$} & Distance between $\mathrm{C}_{7}$ and $\mathrm{S}_{1}$, measured in the vertical axis \\
\hline 6 & DCK & $\mathrm{mm}$ & & Percentage of body height \\
\hline 7 & KPT & degree & Angle of extension & $\begin{array}{l}\text { Defined as a deviation of the } \mathrm{C}_{7}-\mathrm{S}_{1} \text { line from a vertical } \\
\text { position (backward) }\end{array}$ \\
\hline 8 & KPT - & degree & $\begin{array}{l}\text { The angle of the } \\
\text { body bent }\end{array}$ & $\begin{array}{l}\text { Defined as a deviation of the } \mathrm{C}_{7}-\mathrm{S}_{1} \text { line from a vertical } \\
\text { position (forwards) }\end{array}$ \\
\hline 9 & DKP & $\mathrm{mm}$ & \multirow[t]{2}{*}{$\begin{array}{l}\text { Thoracic kyphosis } \\
\text { length }\end{array}$} & Distance between LL and $\mathrm{C}_{7}$ \\
\hline 10 & DKP & $\%$ & & DCK percentage \\
\hline 11 & KKP & degree & $\begin{array}{l}\text { Thoracic kyphosis } \\
\text { angle }\end{array}$ & $\mathrm{KKP}=180-($ Beta+ Gamma $)$ \\
\hline 12 & RKP & $\mathrm{mm}$ & \multirow[t]{2}{*}{$\begin{array}{l}\text { Thoracic kyphosis } \\
\text { height }\end{array}$} & Distance between points $\mathrm{C}_{7}$ and $\mathrm{PL}$ \\
\hline 13 & RKP & $\%$ & & DCK percentage \\
\hline 14 & GKP & $\mathrm{mm}$ & $\begin{array}{l}\text { Thoracic kyphosis } \\
\text { depth }\end{array}$ & $\begin{array}{l}\text { The distance measured horizontally between the vertical lines } \\
\text { passing through points PL and KP }\end{array}$ \\
\hline 15 & DLL & $\mathrm{mm}$ & \multirow[t]{2}{*}{$\begin{array}{l}\text { Lumbar lordosis } \\
\text { length }\end{array}$} & The distance measured between points $\mathrm{S}_{1}$ and KP \\
\hline 16 & DLL & $\%$ & & DCK percentage \\
\hline 17 & KLL & degree & $\begin{array}{l}\text { The angle of lumbar } \\
\text { lordosis }\end{array}$ & $\mathrm{KLL}=180-($ Alfa + Beta $)$ \\
\hline 18 & RLL & $\mathrm{mm}$ & \multirow[t]{2}{*}{$\begin{array}{l}\text { Lumbar lordosis } \\
\text { height }\end{array}$} & Distance between points $S_{1}$ and PL \\
\hline 19 & RLL & $\%$ & & DCK percentage \\
\hline 20 & GLL - & $\mathrm{mm}$ & $\begin{array}{l}\text { Lumbar lordosis } \\
\text { depth }\end{array}$ & $\begin{array}{l}\text { The distance measured horizontally between the vertical lines } \\
\text { passing through points PL and LL }\end{array}$ \\
\hline
\end{tabular}




\begin{tabular}{|c|c|c|c|c|}
\hline \multicolumn{5}{|c|}{ Frontal plane } \\
\hline 21 & KNT - & degree & \multirow{2}{*}{$\begin{array}{l}\text { The angle of torso } \\
\text { flexion to the side in } \\
\text { the frontal plane }\end{array}$} & $\begin{array}{l}\text { Defined as the deviation of the } \mathrm{C}_{7}-\mathrm{S}_{1} \text { line from the vertical } \\
\text { axis to the left }\end{array}$ \\
\hline 22 & KNT & degree & & $\begin{array}{l}\text { Defined as the deviation of the } \mathrm{C}_{7}-\mathrm{S}_{1} \text { line from the vertical } \\
\text { axis to the right }\end{array}$ \\
\hline 23 & KNM & degree & \multirow{3}{*}{ Pelvic tilt angle } & \multirow{3}{*}{$\begin{array}{l}\text { The angle between the horizontal line and the straight line } \\
\text { passing through points M1 and Mp. The right iliac crest } \\
\text { higher "+". } \\
\text { The left iliac crest higher "-". }\end{array}$} \\
\hline 24 & KNM- & degree & & \\
\hline & & & & \\
\hline 25 & UK & $\mathrm{mm}$ & $\begin{array}{l}\text { The maximum } \\
\text { deviation of the } \\
\text { spinous process to } \\
\text { the right }\end{array}$ & \multirow[t]{2}{*}{$\begin{array}{l}\text { Maximal deviation of the spinous process from the vertical } \\
\text { line from } \mathrm{S}_{1} \text {. The distance is measured in a horizontal line. }\end{array}$} \\
\hline 26 & The UK - & $\mathrm{mm}$ & $\begin{array}{l}\text { The maximum } \\
\text { deviation of the } \\
\text { spinous process to } \\
\text { the left. }\end{array}$ & \\
\hline 27 & NK & - & $\begin{array}{l}\text { Number of the } \\
\text { vertebra maximally } \\
\text { distanced to the left } \\
\text { or to the right }\end{array}$ & $\begin{array}{l}\text { The number of the vertebra, counting as } 1 \text {, the first cervical } \\
\text { vertebra }\left(C_{1}\right) \text {. } \\
\text { If the arithmetic mean takes the value e.g. from } 12.0 \text { to } 12.5 \text {, } \\
\text { it is Th5, if from } 12.6 \text { to } 12.9 \text { it is Th6. }\end{array}$ \\
\hline \multicolumn{5}{|c|}{ Transverse plane } \\
\hline 28 & KSM & degree & \multirow[t]{2}{*}{ Pelvic tilt } & $\begin{array}{l}\text { The angle between the line passing through point M1 and } \\
\text { perpendicular to the camera axis and the straight line passing } \\
\text { through points M1 and MP }\end{array}$ \\
\hline 29 & KSM - & degree & & $\begin{array}{l}\text { The angle between the line passing through point Mp and } \\
\text { perpendicular to the camera axis and the straight line passing } \\
\text { through points Ml and MP. Pelvis rotated to the left. }\end{array}$ \\
\hline \multicolumn{5}{|c|}{ Anthropometric parameters } \\
\hline 30 & W.C. & $\mathrm{cm}$ & \multirow{2}{*}{\multicolumn{2}{|c|}{$\begin{array}{l}\text { Measurement of body height (W.C.) and mass (M.C.) was conducted using medical } \\
\text { scales with an accuracy of } 1 \mathrm{~g} \text { and } 1 \mathrm{~mm} \text {. }\end{array}$}} \\
\hline \multirow[t]{2}{*}{31} & M.C. & $\mathrm{kg}$ & & \\
\hline & \multicolumn{4}{|r|}{ Additional parameters } \\
\hline 32 & \multicolumn{4}{|c|}{ Areas - urban/ rural } \\
\hline 33 & \multicolumn{4}{|l|}{ Age } \\
\hline 34 & \multicolumn{4}{|l|}{$\mathrm{Sex}-\mathrm{M} / \mathrm{K}$} \\
\hline
\end{tabular}

Source: own study

In general, the research conducted on the population of 2,361 children aged from 7 to 15 years during six semi-annual editions allowed to record 16,608 observations of 31 parameters describing body posture in particular age categories, Tab. 2. The measuring station that diagnoses body posture using mora projection a computer, a card, software, a display monitor, a printer, and a projection-reception device with a camera to measure the selected parameters of the pelvis-spine complex. Obtaining the spatial picture was possible thanks to displaying 
the line of strictly defined parameters on the child's back and feet. The lines falling on the skin of the child got distorted depending on the configuration of the surface. The applied lens ensured that the imaging of the subject could be received by a special optical system with a camera, then transmitted to the computer monitor. The distortions of the line imaging recorded in the computer memory were processed through a numerical algorithm on the topographic map of the examined surface [11]. To minimize the risk of errors, the study procedure was followed [12]:

1. The habitual posture of the subject (unconstrained, natural, with feet slightly apart, extended knee and hip joints, arms hanging down along torso and eyes looking straight ahead) positioned with the back facing the camera at a proper distance from it. Recording for the purpose of the image analysis should involve the middle phase of free exhalation.

2. Marking the following points on the skin of the subject's back: the most prominent spinous process of the last cervical vertebra $\left(\mathrm{C}_{7}\right)$, the most prominent spinous process of thoracic kyphosis (KP), the most prominent spinous process of lumbar lordosis (LL), the point where thoracic kyphosis connects with lumbar lordosis (PL), lower shoulder blades ( $€ 1$ and $Ł p$ ), posterior superior iliac spines (Ml and $\mathrm{Mp}$ ), vertebra $\mathrm{S}_{1}$.

3. After entering necessary data on the subject (name and surname, year of birth, body weight and height, remarks on the condition of knees and hills, chest, injuries, surgical procedures, locomotor disorders, gait, etc.), the image of the back is stored in the digital computer's memory.

4. The images recorded during the research are compiled without the involvement of subjects.

5. After the mathematical characteristics of the images are saved in the computer's memory, the parameters of spatial body posture are printed.

The statistical analysis covered the measurement results of subjects aged 4 to 18 years during 6 semi-annual editions.

The empirical data were the quantitative and qualitative characteristics (gender, domicile, etc.). The conducted calculations covering the values of position statistics (arithmetic mean, quartiles), the dispersion parameter (standard deviation) and symmetry indicators (asymmetry and concentration indicators) provided a full view of the distribution of the studied features considering gender and age ranges. The significance of changes in mean values during subsequent years within one gender was analysed for selected parameters ( $t$-Student test was applied).

Multiple regression was conducted choosing the optimal subset of explanatory variables. The results allow drawing conclusions related to the quality and dynamics of changes in the 
studied parameters. In addition, comparative analyses of mean values were carried in age groups between genders.

\section{Results}

Tab. 3. The analysis of multiple regression with the selection of the subset of the optimal set of

explanatory variables: town, age, sex, body height and mass, torso flexion and extension and parameters, $1-20 . \mathrm{N}=16608$

\begin{tabular}{|c|c|c|c|c|c|c|c|c|c|c|c|}
\hline \multicolumn{10}{|c|}{ Variable parameters in the model } & \multirow[t]{3}{*}{$\mathrm{R} 2 \%$} & \multirow{3}{*}{$\begin{array}{l}\text { I. } \\
\text { r. }\end{array}$} \\
\hline \multicolumn{2}{|c|}{ Variables } & \multicolumn{8}{|c|}{ With an impact } & & \\
\hline No & Name & Xo & Town & Age & Sex & W.C. & M.C. & KPT & KPT- & & \\
\hline 1 & Alfa & 7.95 & & -0.01 & $\begin{array}{l}- \\
0.2 \\
9\end{array}$ & 0.03 & & $\begin{array}{l}- \\
0.11\end{array}$ & 0.53 & 52.87 & $* * *$ \\
\hline 2 & Beta & 6.94 & 0.19 & -0.01 & & 0.02 & & 0.78 & -0.6 & 49.37 & $* * *$ \\
\hline 3 & $\begin{array}{l}\text { Gamm } \\
\text { a }\end{array}$ & 9.71 & & -0.01 & $\begin{array}{l}0.1 \\
3\end{array}$ & 0.02 & & $\begin{array}{l}- \\
0.28\end{array}$ & 0.55 & 44.44 & $* * *$ \\
\hline 4 & Delta & 24.49 & 0.29 & -0.03 & & 0.08 & & 0.39 & 0.48 & 13.15 & $* * *$ \\
\hline 5 & $\mathrm{DCK}$ & 211.95 & -4.53 & 0.06 & & 1.12 & 0.16 & 0.96 & -0.84 & 27.36 & $* * *$ \\
\hline 6 & $\mathrm{DCK} \%$ & 37.73 & -0.41 & -0.01 & & -0.07 & 0.01 & 0.1 & -0.09 & 44.58 & $* * *$ \\
\hline 9 & DKP & 176.04 & -4.41 & & & 0.91 & 0.21 & 2.95 & -4.28 & 31.22 & $* * *$ \\
\hline 10 & $\mathrm{DKP} \%$ & 82.51 & -0.5 & 0.0 & 0.3 & & 0.01 & 0.6 & -1.05 & 3.14 & $* * *$ \\
\hline 11 & KKP & 165.29 & & 0.02 & & -0.07 & 0.01 & $\begin{array}{l}- \\
0.56\end{array}$ & & 24.84 & $* * *$ \\
\hline 12 & RKP & 120.63 & -4.1 & & & 0.58 & 0.35 & 0.4 & & 29.53 & $* * *$ \\
\hline 13 & $\mathrm{RKP} \%$ & 55.89 & -0.71 & & & & 0.06 & -0.1 & & 19.33 & $* * *$ \\
\hline 14 & GKP & 8.99 & -0.6 & -0.0 & & 0.08 & & 2.12 & -1.38 & 56.05 & $* * *$ \\
\hline 15 & DLL & 174.64 & -2.64 & & $\begin{array}{l}- \\
1.0 \\
3\end{array}$ & 0.68 & & 3.94 & -3.9 & 25.46 & $* * *$ \\
\hline 16 & DLL $\%$ & 79.77 & & 0.01 & & -0.04 & $\begin{array}{l}- \\
0.03\end{array}$ & 0.92 & -0.98 & 38.17 & $* * *$ \\
\hline 17 & KLL & 164.42 & -0.2 & 0.02 & & -0.06 & & $\begin{array}{l}- \\
0.51\end{array}$ & 0.14 & 45.77 & $* * *$ \\
\hline 18 & RLL & 92.99 & & 0.04 & $\begin{array}{l}0.8 \\
4\end{array}$ & 0.53 & $\begin{array}{l}- \\
0.15\end{array}$ & 0.82 & -0.45 & 14.18 & $* * *$ \\
\hline 19 & RLL\% & 44.11 & 0.8 & & & & $\begin{array}{l}- \\
0.06\end{array}$ & 0.09 & & 19.7 & $* * *$ \\
\hline 20 & GLL - & 1.71 & 0.35 & -0.02 & & 0.13 & $\begin{array}{l}- \\
0.02\end{array}$ & 1.95 & -1.3 & 54.03 & $* * *$ \\
\hline
\end{tabular}

\section{Source: own study}


Tab. 4. The analysis of multiple regression with the selection of the subset of the optimal set of

explanatory variables: town, age, sex, body height and mass, torso flexion and extension, and parameters in the frontal plane to the left and right. $\mathrm{N}=16608$

\begin{tabular}{|c|c|c|c|c|c|c|c|c|c|c|c|}
\hline \multicolumn{10}{|c|}{ Variable parameters in the model } & \multirow{3}{*}{$\begin{array}{l}\text { R2 } \\
\%\end{array}$} & \multirow{3}{*}{$\begin{array}{l}\text { I. } \\
\text { r. }\end{array}$} \\
\hline \multicolumn{2}{|c|}{ Variables } & \multicolumn{8}{|c|}{ With an impact } & & \\
\hline $\mathrm{Nr}$ & Name & Xo & Town & Age & Sex & W.C. & M.C. & KNM & KNM- & & \\
\hline 1 & Alfa & 6.88 & 0.4 & -0.01 & -1.0 & 0.02 & 0.03 & -0.12 & 0.14 & 2.34 & $* * *$ \\
\hline 2 & Beta & 14.76 & & -0.0 & & -0.01 & -0.04 & 0.14 & & 4.57 & $* * *$ \\
\hline 3 & Gamma & 6.4 & & -0.01 & 0.44 & 0.06 & & & & 9.32 & $* * *$ \\
\hline 4 & Delta & 28.98 & 0.38 & -0.03 & -0.45 & 0.06 & & & 0.22 & 4.52 & $* * *$ \\
\hline 5 & DCK & $\begin{array}{l}215.9 \\
9\end{array}$ & -5.05 & 0.06 & & 1.15 & & 0.91 & 1.04 & 25.48 & $* * *$ \\
\hline 6 & $\mathrm{DCK} \%$ & 38.77 & -0.45 & -0.01 & & -0.07 & 0.0 & 0.07 & 0.07 & 42.64 & $* * *$ \\
\hline 9 & DKP & $\begin{array}{l}208.8 \\
2\end{array}$ & -6.09 & & 3.11 & 0.79 & & 0.86 & & 16.38 & $* * *$ \\
\hline 10 & DKP $\%$ & 89.87 & -0.82 & 0.01 & 0.92 & -0.03 & -0.03 & & -0.15 & 2.25 & $* * *$ \\
\hline 11 & KKP & 159.3 & & 0.02 & -0.56 & -0.05 & 0.04 & -0.22 & & 5.36 & $* * *$ \\
\hline 12 & RKP & $\begin{array}{l}127.2 \\
3 \\
\end{array}$ & -4.84 & & 1.75 & 0.6 & 0.3 & 0.59 & & 19.2 & $* * *$ \\
\hline 13 & RKP $\%$ & 56.44 & -0.8 & 0.0 & 0.51 & & 0.06 & & & 3.24 & $* * *$ \\
\hline 14 & GKP & 29.92 & -1.23 & & 0.52 & $\begin{array}{l}-0.03 \\
\end{array}$ & -0.08 & 0.34 & & 5.7 & $* * *$ \\
\hline 15 & DLL & $\begin{array}{l}210.5 \\
5 \\
\end{array}$ & -3.78 & & & 0.45 & -0.15 & 0.9 & & 10.4 & $* * *$ \\
\hline 16 & DLL $\%$ & 87.88 & -0.24 & 0.02 & & $\begin{array}{l}-0.11 \\
\end{array}$ & -0.07 & & & 7.36 & $* * *$ \\
\hline 17 & KLL & 159.7 & -0.44 & 0.02 & 0.92 & $\begin{array}{l}-0.01 \\
\end{array}$ & & & -0.23 & 1.49 & $* * *$ \\
\hline 18 & RLL & 99.29 & 0.88 & -0.03 & -1.74 & 0.45 & -0.16 & 0.43 & 0.55 & 7.27 & $* * *$ \\
\hline 19 & RLL $\%$ & 43.52 & 0.89 & -0.0 & -0.51 & & -0.06 & & & 3.43 & $* * *$ \\
\hline 20 & GLL - & 23.69 & & -0.01 & 0.39 & & -0.1 & 0.33 & & 3.62 & $* * *$ \\
\hline
\end{tabular}

Source: own study

Tab. 5. Multiple regression of variable parameters with the selection of the subset of the optimal set $\mathrm{N}=16608$

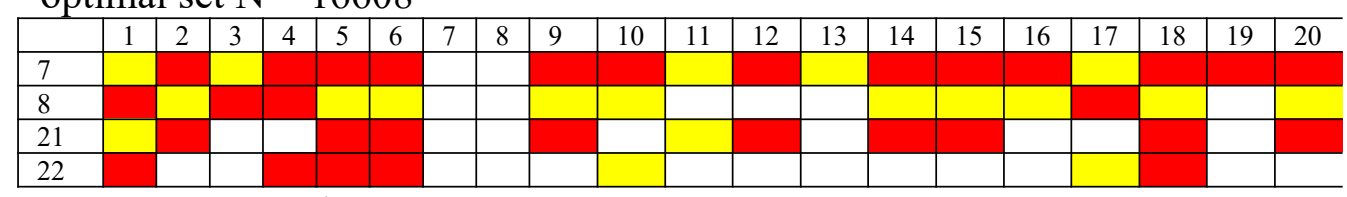

Source: own study

Legend:

Parameters specified vertically influence the horizontal array

red - significant positive impact

yellow - significant negative impact

white - insignificant impact 
Extension and flexion angle in the sagittal plane

The analysis of multiple regression including the choice of the optimal subset of variables covered two influencing parameters such as torso extension angle (KPT) and torso flexion angle (KPT-). The set of variable parameters included the parameters of the spine-pelvis complex: $1-29$ (Tab. 2). The regression (Tab. 3, 5) revealed the following impact: Alpha angle (1) - the inclination angle of the lumbosacral spine was significantly positively influenced by torso flexion angle, and negatively affected by torso extension angle; Beta angle (2) - the inclination angle of the thoraco-lumbar spine was positively influenced by torso extension angle and negatively affected by torso flexion angle; Gamma angle (3) - the inclination angle of the upper thoracic spine was significantly positively influenced by torso flexion angle and negatively affected by torso extension angle, Delta angle (4) - the total of angle values (Alpha+Beta+Gamma) was affected significantly and positively by flexion, extension angle; DCK (5) - the total spine length was significantly and positively influenced by torso extension angle and a negative impact was exerted by torso flexion angle; DCK \% (6) - the percentage of the total spine length W.C. was positively and significantly influenced by torso extension angle and a negative impact was exerted by torso flexion angle; DKP (9) the length of thoracic kyphosis was significantly and positively affected by torso extension angle and negatively by torso flexion angle; DKP \% (10) - the percentage of thoracic kyphosis length DCK was significantly and positively affected by torso extension angle and negatively by torso flexion angle; KKP (11) - thoracic kyphosis angle was significantly and negatively influenced by torso extension angle; RKP (12) - height of thoracic kyphosis was significantly and positively influenced by torso extension angle; RKP \% (13) - the percentage of thoracic kyphosis length DCK was significantly and negatively affected by torso extension angle; GKP (14) - depth of thoracic kyphosis was significantly and positively influenced by torso extension angle and negatively by torso flexion angle; DLL (15) - length of lumbar lordosis was significantly and positively influenced by torso extension angle and negatively by torso flexion angle; DLL \% (16) - the percentage of lumbar lordosis length DCK was significantly and positively influenced by torso extension angle and negatively by torso flexion angle; KLL (17) - lumbar lordosis angle was significantly and positively influenced by torso flexion angle and negatively by torso extension angle; RLL (18) - lumbar lordosis height was significantly and positively influenced by torso extension angle and negatively by torso flexion angle; RLL \% (19) - the percentage of lumbar lordosis height DCK was significantly and positively influenced by torso extension angle, GLL- (20) - lumbar lordosis 
depth was significantly and positively influenced by torso extension angle and negatively by torso flexion angle.

Torso flexion angle to the left and to the right in the sagittal plane

The analysis of multiple regression including the choice of the optimal subset of variables covered two influencing parameters such as torso flexion angle to the right (KNT) and to the left (KNT-). torso angle (KPT-). The set of variable parameters included the parameters of the spine-pelvis complex: 1 - 29 (Tab. 2). The regression (Tab. 4, 5) suggested the following impact on the variables: Alpha angle (1) - the inclination angle of the lumbosacral spine was significantly positively influenced by torso flexion angle to the right, and negatively affected by flexion angle to the left; Beta angle (2) - the inclination angle of the thoraco-lumbar spine was positively and significantly influenced by flexion angle to the left; Delta angle (4) - the total of angle values (Alpha+Beta+Gamma) was affected significantly and positively by flexion angle to the right; DCK (5) - the total spine length was significantly and positively influenced by flexion angle to the left and to the right; DCK \% (6) - the percentage of the total spine length W.C. was positively and significantly influenced by flexion angle to the left and to the right; DKP (9) - the length of thoracic kyphosis was significantly and positively affected by flexion angle to the left; DKP \% (10) - the percentage of thoracic kyphosis length DCK was significantly and negatively affected by flexion angle to the right; KKP (11) thoracic kyphosis angle was significantly and negatively influenced by flexion angle to the left; RKP (12) - height of thoracic kyphosis was significantly and positively influenced by flexion angle to the left; GKP (14) - depth of thoracic kyphosis was significantly and positively influenced by flexion angle to the left; DLL (15) - length of lumbar lordosis was significantly and positively influenced by flexion angle to the left; KLL (17) - lumbar lordosis angle was significantly and negatively influenced by flexion angle to the right; RLL (18) - lumbar lordosis height was significantly and positively influenced by flexion angle to the left and to the right; GLL- (20) - lumbar lordosis depth was significantly and positively influenced by flexion angle to the left.

\section{Discourse}

Due to editorial restrictions as well as a large number of obtained study results, the author deliberately limited himself to the angles of torso flexion and extension in the sagittal and frontal plane. The statistical analysis showed the mutual influence of the values of selected parameters. The research study did not reveal an independent parameter, however, the impact level varied. This suggests the mutual relationship of particular body posture elements and 
that the change in one of them influences the change in another one. It is also important to be aware of the positive or negative impact we exert.

Research on body posture using the photogrammetric method with the group of 480 first-tothird form pupils from primary school has shown those body posture parameters are interdependent, that the most dependent parameters include torso tilt angle, and the least dependent parameter is thoracic kyphosis length [13]. Based on the study with a population of 153 girls, Wilczyński [14] observed asymmetry in 18 subjects at the age of 14, 16 subjects aged 15 years of age, and 38 cases among 16-year-old girls. When analysing the correlation coefficients between physique and posture parameters and the time of simple reaction to a visual stimulus, he found a direct relationship between the angle of torso flexion and extension in the sagittal plane in 14-year-old girls. The studies [15, 16, 17] have shown that torso asymmetry has a significant effect on the distribution of body weight on the load bearing surfaces of the locomotor system. Persistent load asymmetry may lead to overload and deformation changes and eventually result in pain in the lower extremities and spine. According to some publications [16, 17, 18, 19], spine asymmetry is determined by pathomechanical changes associated with the emergence and development of scoliosis. Each change in shape triggers a chain of changes in structures and organs located near the spine and further form it. Reasons for such changes may be different. These can include being anatomopathological changes. The deviation from the spinal axis causes the displacement of individual body segments. In consequence, changes within paravertebral soft-tissue elements occur leading to their contracture on the side of curvature concavity and stretch on the side of convexity.

There are different causes of postural errors and subsequent defects of body posture ranging from genetic conditions, statodynamic disorders, various diseases to epigenetic factors. A rich literature exists which describes the impact of these factors, however, the interdependence between individual elements of body posture has not been studied yet. The relationships under discussion have not only scientific or cognitive value, but in the first place, they provide practical tips to everyone who conducts corrective and compensation exercises [20]. Interestingly, there is no significant influence of the values of both studied angles on the inclination angle of pelvis to the left and right, torso inclination angle in the frontal plane, and sagittal torsion angle to the left and right. It should be deemed that the angle values were too small to determine a statistically significant correlation as the qualification of individuals for the research program excluded vivid postural defects and mistakes. 


\section{Conclusions}

1. Spinal parameters are significantly and positively affected by the angle of torso extension in the sagittal plane and the angle of flexion to the left in the frontal plane and negatively influenced by the flexion angle in the sagittal plane.

2. The values of torso extension and flexion angles in the sagittal plane and torso flexion to the left and right in the frontal plane have a significant and positive impact on the total length of the spine $\left(\mathrm{C}_{7}-\mathrm{S}_{1}\right)$ and the percentage of growth $(\mathrm{DCK} \%)$, the Delta angle and the height of lumbar lordosis. The inclination angle of the lumbosacral spine, the total spinal length and the percentage of body height, and the height of lumbar lordosis account for the parameters that are most dependent on the angles describing the vertical orientation of the axial organ.

3. The significant negative impact on the spine parameters is remarkably lower. The most negatively dependent parameters include lumbosacral inclination angle, the length and angle of thoracic kyphosis, and lumbar lordosis angle.

4. Hardly any influence of the analysed angles on pelvis parameters demonstrated herein requires further studies on the impact of foot parameters on the parameters of pelvis and spine.

5. The significant correlations of flexion and extension angles in the sagittal plane, as well as the flexion angle in the frontal plane, should be taken into consideration in the process of correcting body posture defects and errors.

\section{Literature}

1. Barcińska I., Dubielis A., Postural defects, [at:] Kiperski J. (ed.), Medical Rehabilitation, PZWL, Warsaw 2006, p. 298.

2. Mrozkowiak M., Jazdończyk P., Correlations between the Spine-Pelvis System and Feet in Girls and Boys Aged 4 to 18 Years. Journal of Education, Health and Sport. 2015;5(7):226-250.

3. Mrozkowiak M, Cybul D., What correlations are there between body mass and height and torso parameters among 7-13-year-old children, Functional Physiotherapy, no. 11 (20), pp. 16-20.

4. Mirosław Mrozkowiak, Mariusz Posłuszny, Marek Sokołowski, Alicja Kaiser, Tomasz Szurmik, The correlations of parameters describing body trunk and feet of adolescents in the light of health security, [ed.] Marek Sokołowski, Mirosław 
Mrozkowiak, Andrzej Tomczak, [at] Aspects of Poland's national security system challenges and risks, Warsaw, 2017, pp. 325-338.

5. Mrozkowiak M., Sokołowski M., Relationships between characteristics of the spinepelvis system and feet in boys aged 7 to 13 years. Journal of Education, Health and Sport. 2016;6(5):177-192.

6. Sokołowski Marek, Mrozkowiak Mirosław. Correlations between selected characteristics that describe body trunk and feet in children and young people aged 4 to 18 years. Journal of Education, Health and Sport formerly Journal of Health Sciences 2017; 7(6):281-316.

7. Mirosław Mrozkowiak, Mariusz Posłuszny, Marek Sokołowski, Alicja Kaiser, Tomasz Szurmik, Relationships between the parameters of feet in adolescents in the light of health security [ed.] Marek Sokołowski, Mirosław Mrozkowiak, Andrzej Tomczak, [at] Aspects of Poland's national security system - challenges and risks, Warsaw, 2017, pp. 325-338.

8. Mrozkowiak M., Posłuszny M., Sokołowski M., Kaiser A., the incidence of significant relationships between selected parameters of feet and parameters of trunk in adolescents aged 14-18 years. Journal of Education, Health and Sport. 2018;8(2):305-319.

9. Mrozkowiak M., Sokołowski M., Kaiser A., Posłuszny M., The incidence of significant relationships between selected parameters of feet and parameters of trunk in children aged 4, 5 and 6 years. Journal of Education, Health and Sport. 2018;8(2):320-333.

10. Myers T.W., The food. Understanding the Arches. Massage \& Bodywork Magazine, September/October, 1997.

11. Świerc A., 2006, Computer diagnostics of body posture - guidelines, Czernica Wrocławska.

12. Mrozkowiak M., Modulation, impact and relationships of selected body posture parameters in children and adolescents aged between 4 and 18 years in the light of mora projection, Publishing House of Kazimierz Wielki University, Bydgoszcz, 2015, v. I, II.

13. Drzał-Grabiec J. Szczepanowska-Wołowiec B., The correlations of selected body posture parameters, Young Sport Science of Ukraine, 2012, v. 3. pp. 82-86. 
14. Wilczyński J., Differences in the quality of body posture between girls examined by means of spatial photogrammetry - Moire, Physical Culture 2007, no. 1-2, pp. 1214.

15. Bąk S., Physiological reasons for deviations in the physical development of school youth, [at:] Correction and compensation in the development of school adolescents, (ed.) Trześniowski R., Maszczak T., SiT, Warsaw 1977, pp. 38-41.

16. Nowotny J., Saulicz E., Neurophysiological aspects of correcting deviations from the normal body posture, [at:] Spine dysfunctions - diagnostics, therapy, [ed.] Nowotny J., AWF Katowice 1993.

17. Żak T., Dziak A., Orthopaedic propaedeutics, PZWL, Warsaw 1970.

18. Cieśla T., Some aspects of compensation in lateral spinal curvatures, Methodology and Research Bulleting, AWF, Katowice 1993, no. 3, pp. 29-38.

19. Tylman D., Compensation pelvic changes in lateral spinal curvatures, [at:], Correction and compensation in the development of school adolescents, (ed.) Trześniowski T., Maszczak T., SiT, Warsaw 1974, pp. 107-111.

20. Drzał-Grabiec, Szczepanowska-Wołowiec B., Relationships of selected body posture parameters, Young Science of Ukraine, 2012, v. 3, pp. 82-86. 